\title{
Carbon dioxide - a complex gas in a complex circulation: Its effects on systemic hemodynamics and oxygen transport, cerebral, and splanchnic circulation in neonates after the Norwood procedure
}

\author{
Jia Li, MD, PhD, Gencheng Zhang, MD, PhD, Helen Holtby, MD, Bruno Bissonnette, MD, Golden Wang, MD,
}

Andrew N. Redington, MD, and Glen S. Van Arsdell, MD

\begin{abstract}
Objective: Carbon dioxide is suggested to increase oxygen delivery after the Norwood procedure. We sought to quantitatively define the effects of stepwise increases in arterial carbon dioxide tension on systemic oxygen transport and cerebral and splanchnic circulation after the Norwood procedure.
\end{abstract}

\begin{abstract}
Methods: Seven sedated, paralyzed, and mechanically ventilated neonates were studied after the Norwood procedure. Arterial carbon dioxide tension increased from 40-50-60 mm Hg using inspired carbon dioxide. Each step was 30 minutes. Pulmonary and systemic blood flow, vascular resistance, and oxygen delivery were calculated with the measurement of oxygen consumption and blood gases and pressures from the aorta, superior vena cava, and pulmonary vein. Plasma epinephrine and norepinephrine were measured. Cerebral and splanchnic oxygen saturations were measured by near-infrared spectroscopy, and cerebral blood flow velocity was measured by transcranial Doppler.

Results: Stepwise increase in arterial carbon dioxide tension was associated with a decrease in systemic vascular resistance $(P<.001)$ and an increase in systemic blood flow $(P<.01)$ and oxygen delivery $(P<.0001)$, but not with significant changes in total pulmonary vascular resistance and pulmonary blood flow. Cerebral oxygen saturation increased $(P<.0001)$, and splanchnic oxygen saturation decreased $(P<.01)$. Oxygen consumption decreased $(P<.01)$, and epinephrine and norepinephrine increased $(P<.01$ and .05$)$.

Conclusion: Moderate hypercapnia increases systemic blood flow because of its effect on systemic vascular resistance after the Norwood procedure. The increase in systemic blood flow is primarily a consequence of increased cerebral blood flow that compromises splanchnic circulation. The decrease in oxygen consumption improves oxygen transport, but the increase in catecholamines may be undesirable. Clinical use of carbon dioxide aiming to improve oxygen delivery should be with caution.
\end{abstract}

The important goal and challenge in the management of neonates after the Norwood procedure is to maintain adequate systemic blood flow (Qs) and oxygen delivery $\left(\mathrm{DO}_{2}\right)$ to sustain tissue oxygenation. In these neonates, $\mathrm{DO}_{2}$ is reduced because of impaired myocardial function, and systemic oxygen consumption $\left(\mathrm{VO}_{2}\right)$ is increased as a result of cardiopulmonary bypass (CPB) and secondary systemic inflammatory response. ${ }^{1}$ The complex pathophysiology with univentricular and parallel circulation profoundly affects oxygen transport after the Norwood procedure and seriously limits the postoperative management. The lack of adequate animal models of single ventricle anatomy or physiology makes it difficult to study. ${ }^{2-4}$ Clinical studies have been limited because of the use of indirect indicators of arterial

\footnotetext{
From The Heart Center, Hospital for Sick Children, Toronto, Ontario, Canada.

This study was supported by the Heart and Stroke Foundation of Canada (J.L., A.N.R and G.S.V).

Received for publication Aug 24, 2007; revisions received Oct 17, 2007; accepted for publication Feb 25, 2008.

Reprint requests: Jia Li, MD, PhD, Division of Cardiology, The Heart Center, Hospital for Sick Children, Toronto, Ontario, Canada, M5G 1X8 (E-mail: jia.li@yahoo. com).

J Thorac Cardiovasc Surg 2008;136:1207-14

$0022-5223 / \$ 34.00$

Copyright (c) 2008 by The American Association for Thoracic Surgery

doi:10.1016/j.jtcvs.2008.02.096
}

and superior vena caval oxygen saturations as surrogates of $\mathrm{DO}_{2}{ }^{5,6}$

Carbon dioxide $\left(\mathrm{CO}_{2}\right)$ has been suggested to increase $\mathrm{DO}_{2}$ in neonates both before and after the Norwood procedure. ${ }^{2-6}$ Consequently, it is a common practice to maintain a relatively high arterial $\mathrm{CO}_{2}$ tension $\left(\mathrm{PaCO}_{2}\right)$ mostly by hypoventilation. It is believed that the potent pulmonary vasoconstrictive effect of $\mathrm{CO}_{2}$ decreases pulmonary blood flow (Qp), and Qp:Qs thereby increases Qs. This may be incorrect. As we have recently reported, using directly measured systemic hemodynamics and oxygen transport, Qp has little impact on $\mathrm{DO}_{2}$ in the presence of mechanical limitation by the Blalock-Taussig shunt and relative fixed total pulmonary vascular resistance (tPVR) (inclusive of the resistance of the Blalock-Taussig shunt and pulmonary vascular bed), and $\mathrm{DO}_{2}$ is mostly determined by SVR. ${ }^{1}$ Given the potent vasodilating effect of $\mathrm{CO}_{2}$ on systemic circulation, ${ }^{7}$ particularly the cerebral vascular bed, ${ }^{8,9}$ it was hypothesized that the increase in Qs and $\mathrm{DO}_{2}$ by $\mathrm{CO}_{2}$ may be the result of its effect on systemic circulation rather than the pulmonary vasculature, and that the increase in Qs may be the result of an increase in cerebral blood flow instead of splanchnic perfusion.

Near-infrared spectroscopy (NIRS) measures the equilibrium of oxyhemoglobin and deoxyhemoglobin in a mixture 


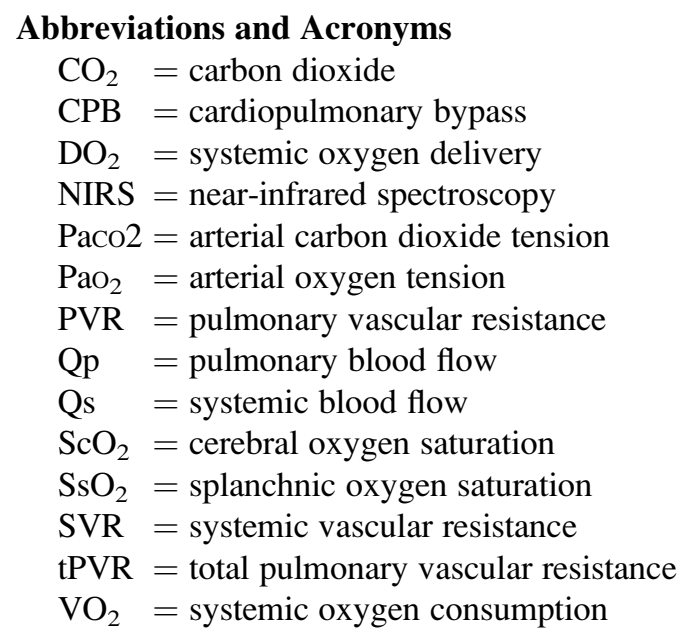

of veins, arteries, and capillaries in the underlying tissue and provides a noninvasive, continuous method to monitor regional tissue oxygenation. ${ }^{10}$ NIRS has been extensively evaluated in the cerebral ${ }^{10}$ and splanchnic ${ }^{11}$ circulations of newborn infants and was adapted to continuously monitor cerebral oxygen saturation $\left(\mathrm{ScO}_{2}\right)$ and splanchnic oxygen saturation $\left(\mathrm{SsO}_{2}\right)$ in the present study.

This study aimed to quantitatively define the effects of a stepwise increase in $\mathrm{PaCO}_{2}$ on the systemic hemodynamics, oxygen transport, and redistribution of systemic $\mathrm{DO}_{2}$ between cerebral and splanchnic circulations in neonates during the early postoperative period after the Norwood procedure.

\section{MATERIALS AND METHODS \\ Patients}

This study was approved by the Research Ethics Board at the Hospital for Sick Children, Toronto, Canada. Written informed consent was obtained from the parents of 7 neonates (4 boys and 3 girls, age range 4-7 days) undergoing the classic Norwood procedure with Blalock-Taussig shunt between September of 2004 and October of 2006. The clinical characteristics of the patients are shown in Table 1. Neonates undergoing the Norwood procedure with right ventricular to pulmonary arterial shunt or the Hybrid procedure with bilateral pulmonary artery bands and arterial duct stent during this period were excluded from the present study in the concern of their different characteristics in systemic hemodynamics and oxygen transport ${ }^{12}$ and potential different responses to $\mathrm{CO}_{2}$.

\section{Intraoperative Procedures}

All patients were intubated with cuffed endotracheal tubes (MicrocuffHeidelberg-Pediatric, Microcuff GmbH, Weinheim, Germany). A central venous line was inserted preoperatively through the internal jugular vein or the subclavian vein to the superior vena cava just above the atrium junction. A standard Norwood procedure with the 3.5-mm right modified Blalock-Taussig shunt was performed in all patients. Circulatory arrest was performed in 6 patients for 1 to 46 minutes and selected cerebral perfusion in 6 patients for 30 to 70 minutes at 30 to $35 \mathrm{~mL} / \mathrm{min} / \mathrm{kg}$ (Table 1). Phenoxybenzamine $(0.25 \mathrm{mg} / \mathrm{kg})$ was given in the heart-lung machine circuit after initiation of $\mathrm{CPB}$. Before termination of $\mathrm{CPB}$, milrinone
$(100 \mu \mathrm{g} / \mathrm{kg})$ was given and dopamine $(5 \mu \mathrm{g} / \mathrm{kg} / \mathrm{min})$ was initiated. A pulmonary venous line was inserted into the orifice of the right upper pulmonary vein.

\section{Postoperative Management}

The central temperature (esophageal) was maintained between $36^{\circ} \mathrm{C}$ and $37^{\circ} \mathrm{C}$. Postoperative monitoring included arterial, superior vena caval, and pulmonary venous pressures, and heart rate. Sedation consisted of continuous intravenous infusion of morphine and intermittent injections of a muscle relaxant (pancuronium). Patients received time-cycled pressure control/ pressure support ventilation. Hemoglobin was maintained between 14 and $16 \mathrm{mg} / \mathrm{dL}$. Inotropic and vasoactive agents (dopamine, milrinone, and phenoxybenzamine) and volume infusions (5\% albumin or blood) were administered according to our standard protocol. ${ }^{13}$

\section{Methods of Measurements}

Systemic oxygen consumption. $\mathrm{VO}_{2}$ was measured continuously using an AMIS2000 respiratory mass spectrometer (Innovision $\mathrm{A} / \mathrm{S}$, Odense, Denmark). This is a sensitive and accurate method for continuous gas analysis that allows simultaneous measurements of multiple gas fractions. ${ }^{1}$ Inspired and end-tidal partial pressures of $\mathrm{CO}_{2}$ were continuously monitored using inlet sampling from the connection of the ventilator circuit to the endotracheal tube. This was used to estimate the rate of $\mathrm{CO}_{2}$ delivery into the inspired gas mixture. ${ }^{14}$ The setup of the $\mathrm{CO}_{2}$ delivery and respiratory mass spectrometer with the ventilator circuit is described elsewhere. ${ }^{15}$ Calculations of hemodynamics and oxygen transport. Blood samples were taken from the arterial, superior vena caval, and pulmonary venous lines for the measurements of blood gases. Qp, Qs, SVR, tPVR, $\mathrm{DO}_{2}$, and oxygen extraction ratio $\left(\mathrm{ERO}_{2}\right)$ were calculated using standard equations (Table 2).

Regional oxygenation. Measurements of cerebral and splanchnic oxygenation were made using NIRS to measure $\mathrm{ScO}_{2}$ and $\mathrm{SsO}_{2}$. The 2 NIRS probes (Somanetics INVOS 5100A, Troy, Mich) were placed in the midline on the forehead of the patient $\left(\mathrm{ScO}_{2}\right)$ and slightly to the right of midline on the thoracic-lumbar flank $\left(\mathrm{SsO}_{2}\right),{ }^{16}$ and recordings were made at 1-minute intervals.

Cerebral blood flow velocity. The flow velocity was measured with transcranial Doppler with a $2 \mathrm{MHz}$ pulse-wave ultrasound transducer, which was fixed above the zygomatic arch (Medasonics Inc, Fremont, Calif) and interrogated the portion of middle cerebral artery near its junction with the anterior cerebral artery. ${ }^{9}$

Plasma norepinephrine and epinephrine. An arterial blood sample of $2 \mathrm{~mL}$ was withdrawn into an EDTA tube. The simultaneous determination of plasma norepinephrine and epinephrine was measured by high-performance liquid chromatography coupled with electrochemical detection. ${ }^{17}$

\section{Study Protocol}

The study protocol was instituted during the period of 48 to 72 hours after the Norwood procedure when a relatively cardiorespiratory steady state was achieved. Inspiratory $\mathrm{O}_{2}$ fraction was 0.21 to 0.25 . The protocol consisted of 4 stages. At baseline, $\mathrm{PaCO}_{2}$ was adjusted to $40 \mathrm{~mm} \mathrm{Hg}$ by modifying minute ventilation. Subsequently, $\mathrm{CO}_{2}$ was delivered to the inspired gas mixture to reach $\mathrm{PaCO}_{2}$ tensions of 50 and $60 \mathrm{~mm} \mathrm{Hg}$ sequentially. Finally, additional $\mathrm{CO}_{2}$ was withdrawn and the measurements were repeated at a $\mathrm{PaCO}_{2}$ of approximately $40 \mathrm{~mm} \mathrm{Hg}$. Each stage was for $30 \mathrm{~min}-$ utes. At the end of each stage, blood gases (including arterial lactate), systemic hemodynamics and oxygen transport, $\mathrm{ScO}_{2}$ and $\mathrm{SsO}_{2}$, and cerebral arterial blood flow velocity were recorded, and arterial blood samples were taken for the measurements of plasma epinephrine and norepinephrine. Before the study, echocardiography was performed to ensure that the aortic arch and Blalock-Taussig shunt were unobstructed. 
TABLE 1. Clinical data for the 7 patients

\begin{tabular}{|c|c|c|c|c|c|c|c|c|}
\hline Patient & Age (d) & Weight (kg) & $\operatorname{BSA}\left(\mathrm{m}^{2}\right)$ & CPB (min) & $\operatorname{ACC}(\min )$ & $\begin{array}{l}\text { Circulatory } \\
\text { arrest (min) }\end{array}$ & $\begin{array}{c}\text { Cerebral } \\
\text { perfusion (min) }\end{array}$ & Diagnosis \\
\hline 1 & 7 & 4 & 0.25 & 167 & 64 & 17 & 44 & HLHS, AS, MS \\
\hline 2 & 6 & 2.9 & 0.2 & 142 & 62 & 1 & 62 & HLHS, AS, MS \\
\hline 3 & 5 & 4.5 & 0.28 & 103 & 75 & 45 & 30 & TA, TGA, IAA \\
\hline 4 & 7 & 3.6 & 0.24 & 156 & 86 & 0 & 0 & $\begin{array}{l}\text { TGA, hypoplastic aortic arch, } \\
\text { criss-cross heart, VSDs }\end{array}$ \\
\hline 5 & 5 & 2.5 & 0.18 & 170 & 126 & 46 & 60 & HLHS, AA, MS \\
\hline 6 & 4 & 4.2 & 0.27 & 124 & 99 & 44 & 49 & HLHS, MA, AA, TAPVC \\
\hline 7 & 7 & 3.2 & 0.21 & 164 & 66 & 9 & 54 & TA, TGA, Hypo AA \\
\hline
\end{tabular}

$A A$, Aortic atresia; $A S$, aortic stenosis; $A C C$, aortic crossclamp; $B S A$, body surface area; $C P B$, cardiopulmonary bypass; $H L H S$, hypoplastic left heart syndrome; $H y p o$ AA, hypoplastic aortic arch; $I A A$, interrupted aortic arch; $L V$, left ventricle; $M A$, mitral atresia; $M S$, mitral stenosis; $T A$, tricuspid atresia; $T A P V C$, total abnormal pulmonary venous connection; $T G A$, transposition of great arteries; $V S D$, multiple ventricular septal defect.

\section{Statistics}

The results are given as mean \pm standard deviation. The data, collected at 4 levels of $\mathrm{PaCO}_{2}(40,50$, and $60 \mathrm{~mm} \mathrm{Hg}$, and then $40 \mathrm{~mm} \mathrm{Hg}$ ), were analyzed by repeated-measures analysis of variance for quadratic effect. A quadratic effect was indicated by a statistically significant parameter estimate for the time sequence effect. The actual estimate for the inverted parabolas was negative, indicating a return toward baseline for the outcome. Pairwise comparison was performed between the data at different levels of $\mathrm{CO}_{2}$. The overall $P$ value and adjusted $P$ value for multiple comparisons were calculated using the Tukey-Kramer adjustment. We used the statistical software SAS version 8.2 (Cary, NC).

\section{RESULTS \\ Patients}

All 7 patients received an infusion of milrinone (0.66$0.99 \mu \mathrm{g} / \mathrm{kg} / \mathrm{min}$ ), and 3 of them received phenoxybenzamine $(0.5-2.0 \mathrm{mg} / \mathrm{kg} / \mathrm{d})$ during the study period. Dopamine had been terminated within the first 36 hours in all patients. None of the patients received epinephrine or norepinephrine during the postoperative period. Patients were extubated 4 to 25 days (median 9 days) after the operation.

\section{Changes During the Study Protocol}

The stepwise increase in $\mathrm{PaCO}_{2}$ from $40 \pm 4$ to $53 \pm 5$ to $61 \pm 6 \mathrm{~mm} \mathrm{Hg}$ led to a decrease in arterial $\mathrm{pH}$ from $7.39 \pm$

TABLE 2. Equations using oxygen consumption to calculate hemodynamics and oxygen transport parameters

\begin{tabular}{ll}
\hline \multicolumn{1}{c}{ Parameters } & \multicolumn{1}{c}{ Equations } \\
\hline $\mathrm{Qp}\left(\mathrm{L} / \mathrm{min} / \mathrm{m}^{2}\right)$ & $\mathrm{VO}_{2} /\left(\mathrm{CpvO}_{2}-\mathrm{CaO}_{2}\right)$ \\
$\mathrm{Qs}\left(\mathrm{L} / \mathrm{min} / \mathrm{m}^{2}\right)$ & $\mathrm{VO}_{2} /\left(\mathrm{CaO}_{2}-\mathrm{CvO}_{2}\right)$ \\
$\mathrm{SVR}\left(\right.$ Wood unit $\left.\times \mathrm{m}^{2}\right)$ & $(\mathrm{MAP}-\mathrm{MVP}) / \mathrm{Qs}$ \\
$\mathrm{tPVR}\left(\right.$ Wood unit $\left.\times \mathrm{m}^{2}\right)$ & $(\mathrm{MAP}-\mathrm{MPVP}) / \mathrm{Qp}$ \\
$\mathrm{DO}_{2}\left(\mathrm{~mL} / \mathrm{min} / \mathrm{m}^{2}\right)$ & $\mathrm{Qs} \times \mathrm{CaO}_{2}$ \\
$\mathrm{ERO}_{2}$ & $\mathrm{VO}_{2} / \mathrm{DO}_{2}$ \\
\hline
\end{tabular}

$\mathrm{CaO}_{2}$, Arterial oxygen content; $\mathrm{CpvO}_{2}$, arterial pulmonary venous content; $\mathrm{CvO}$, arterial superior vena caval oxygen content; $\mathrm{DO}_{2}$, oxygen delivery; $E R O_{2}$, oxygen extraction ratio; $M A P$, mean arterial pressure; $M V P$, mean venous pressure $M P V P$, mean pulmonary venous pressure, respectively; $Q p$, pulmonary blood flow; $Q s$, systemic blood flow; $S A P$, systolic arterial pressure; $S V R$, systemic vascular resistance; $t P V R$, total pulmonary vascular resistance (including the resistance from the BT shunt and pulmonary vascular bed); $\mathrm{VO}_{2}$, systemic oxygen consumption.
0.05 to $7.28 \pm 0.07$ to $7.23 \pm 0.08(P<.0001)$ (Table 3 ; Figure 1). This was not associated with any significant change in tPVR, Qp, $\mathrm{SaO}_{2}$, or pulmonary venous $\mathrm{O}_{2}$ saturation. The stepwise increase in $\mathrm{PaCO}_{2}$ was associated with a significant decrease in SVR $(P<.001)$ and Qp:Qs $(P<.05)$, and a significant increase in arterial oxygen tension $\left(\mathrm{PaO}_{2}\right)(P<$ $.0001)$, Qs $(P<.01)$, and $\mathrm{DO}_{2}(P<.0001)$. A significant decrease in central body temperature $(P<.05), \mathrm{VO}_{2}(P<$ $.01), \mathrm{ERO}_{2}(P<.01)$, and lactate $(P<.001)$ were observed. Norepinephrine $(P<.05)$ and epinephrine $(P<.01)$ significantly increased. Cerebral arterial blood flow peak velocity and $\mathrm{ScO}_{2}$, as well as superior vena caval $\mathrm{O}_{2}$ saturation, significantly increased $(P<.0001$ for all $)$, whereas $\mathrm{SsO}_{2}$ significantly decreased $(P<.01)$. These changes were significantly greater when $\mathrm{PaCO}_{2}$ increased from 40 to $50 \mathrm{~mm}$ $\mathrm{Hg}$ compared with $\mathrm{PaCO}_{2}$ from 50 to $60 \mathrm{~mm} \mathrm{Hg}$, including $\mathrm{PaO}_{2}(P<.0001), \mathrm{VO}_{2}(P<.05)$, lactate $(P<.05)$, cerebral arterial blood flow peak velocity $(P<.01), \mathrm{ScO}_{2}(P<$ $.0001)$, superior venous $\mathrm{O}_{2}$ saturation $(P<.0001)$, and norepinephrine $(P<.05) . \mathrm{DO}_{2}$ increased significantly at both stages of $\mathrm{PaCO}_{2}(P<.05)$. The changes in the remaining variables (temperature, SVR, Qs, Qp:Qs, $\mathrm{CO}, \mathrm{ERO}_{2}$ ) did not achieve statistical significance between either of the 2 sequential stages, despite the significant changes over the 3 levels of $\mathrm{PaCO}_{2}$. There was a small although insignificant increase in heart rate and arterial blood pressure over the stepwise increase in $\mathrm{PaCO}_{2}$. As $\mathrm{PaCO}_{2}$ decreased from $60 \pm$ $6 \mathrm{~mm} \mathrm{Hg}$ to $44 \pm 5 \mathrm{~mm} \mathrm{Hg}$ with discontinuation of added $\mathrm{CO}_{2}$, these variables returned toward baseline.

The levels of norepinephrine and epinephrine at baseline $\mathrm{PaCO}_{2}(40 \mathrm{~mm} \mathrm{Hg})$ varied widely between patients (3.4-25.0 $\mathrm{nmol} / \mathrm{L}$ for norepinephrine and $0.1-14.0 \mathrm{nmol} / \mathrm{L}$ for epinephrine). The levels of norepinephrine and epinephrine at each level of $\mathrm{PaCO}_{2}$ were not correlated with $\mathrm{VO}_{2}$ or any of hemodynamics and oxygen transport variables $\left(\mathrm{r}^{2}<0.20, P>.05\right.$ for all $)$.

\section{DISCUSSION}

This is the first quantitative assessment of the effects of moderate hypercapnia with respiratory acidosis on systemic 
TABLE 3. Arterial blood gas, systemic, cerebral and splanchnic oxygen transport, and circulating norepinephrine and epinephrine during the staged increases of carbon dioxide in 7 neonates after the Norwood procedure

\begin{tabular}{|c|c|c|c|c|}
\hline & Baseline & Added $\mathrm{CO}_{2} \mathrm{I}$ & Added $\mathrm{CO}_{2}$ II & $\mathrm{CO}_{2}$ discontinued \\
\hline $\mathrm{PaCO}_{2}(\mathrm{~mm} \mathrm{Hg})^{\mathrm{a}}$ & $40 \pm 4^{\mathrm{g}}$ & $53 \pm 5^{\mathrm{g}}$ & $61 \pm 6^{\mathrm{e}}$ & $43 \pm 5$ \\
\hline $\mathrm{pH}^{\mathrm{a}}$ & $7.39 \pm 0.05^{\mathrm{g}}$ & $7.28 \pm 0.07^{\mathrm{g}}$ & $7.23 \pm 0.08^{\mathrm{e}}$ & $7.36 \pm 0.06$ \\
\hline Temperature $\left({ }^{\circ} \mathrm{C}\right)^{\mathrm{d}}$ & $36.4 \pm 0.2$ & $36.2 \pm 0.1$ & $36.0 \pm 0.3$ & $36.2 \pm 0.2$ \\
\hline Heart rate (beats/min) & $151 \pm 17$ & $156 \pm 16$ & $162 \pm 10$ & $156 \pm 13$ \\
\hline Mean arterial pressure $(\mathrm{mm} \mathrm{Hg})$ & $48 \pm 7$ & $48 \pm 6$ & $50 \pm 7$ & $45 \pm 7$ \\
\hline $\mathrm{PaO}_{2}(\mathrm{~mm} \mathrm{Hg})^{\mathrm{a}}$ & $41.2 \pm 7.1^{\mathrm{g}}$ & $47.5 \pm 7.6$ & $49.4 \pm 7.1^{\mathrm{f}}$ & $41.2 \pm 8.1$ \\
\hline $\mathrm{SaO}_{2}(\%)$ & $78 \pm 7$ & $80 \pm 6$ & $78 \pm 5$ & $76 \pm 7$ \\
\hline $\mathrm{SsvcO}_{2}(\%)^{\mathrm{a}}$ & $58 \pm 14^{\mathrm{e}}$ & $67 \pm 11$ & $67 \pm 9^{f}$ & $57 \pm 13$ \\
\hline $\mathrm{SpvO}_{2}(\%)$ & $96 \pm 3$ & $95 \pm 4$ & $94 \pm 4$ & $95 \pm 2$ \\
\hline tPVR (Wood unit $\times \mathrm{m}^{2}$ ) & $18 \pm 11$ & $15 \pm 7$ & $16 \pm 8$ & $16 \pm 6$ \\
\hline SVR $\left(\text { Wood unit } \times \mathrm{m}^{2}\right)^{\mathrm{b}}$ & $17 \pm 8$ & $12 \pm 3$ & $10 \pm 6$ & $16 \pm 6$ \\
\hline $\mathrm{Qp}\left(\mathrm{L} / \mathrm{min} / \mathrm{m}^{2}\right)$ & $2.7 \pm 1.0$ & $2.7 \pm 1.0$ & $2.8 \pm 1.3$ & $2.6 \pm 1.0$ \\
\hline $\mathrm{Qs}\left(\mathrm{L} / \mathrm{min} / \mathrm{m}^{2}\right)^{\mathrm{c}}$ & $2.6 \pm 1.3$ & $3.5 \pm 1.3$ & $4.1 \pm 1.5^{\mathrm{h}}$ & $2.6 \pm 0.9$ \\
\hline Qp:Qs ${ }^{\mathrm{d}}$ & $1.1 \pm 0.3$ & $0.8 \pm 0.2$ & $0.7 \pm 0.3$ & $1.1 \pm 0.3$ \\
\hline $\mathrm{DO}_{2}\left(\mathrm{~mL} / \mathrm{min} / \mathrm{m}^{2}\right)^{\mathrm{a}}$ & $386 \pm 214^{\mathrm{h}}$ & $503 \pm 196^{\mathrm{h}}$ & $609 \pm 232^{g}$ & $369 \pm 153$ \\
\hline $\mathrm{VO}_{2}\left(\mathrm{~mL} / \mathrm{min} / \mathrm{m}^{2}\right)^{\mathrm{c}}$ & $86 \pm 18^{\mathrm{h}}$ & $79 \pm 19$ & $78 \pm 20$ & $86 \pm 22$ \\
\hline $\mathrm{ERO}_{2}^{\mathrm{c}}$ & $0.27 \pm 0.14$ & $0.17 \pm 0.06$ & $0.14 \pm 0.07^{\mathrm{g}}$ & $0.26 \pm 0.11$ \\
\hline Lactate $(\mathrm{mmol} / \mathrm{L})^{\mathrm{b}}$ & $1.4 \pm 0.4^{\mathrm{h}}$ & $1.1 \pm 0.2$ & $1.0 \pm 0.2^{\mathrm{g}}$ & $1.2 \pm 0.3$ \\
\hline Cerebral arterial blood flow peak velocity $(\mathrm{cm} / \mathrm{sec})^{\mathrm{a}}$ & $56 \pm 2^{\mathrm{g}}$ & $80 \pm 11$ & $83 \pm 14^{\mathrm{h}}$ & $67 \pm 8$ \\
\hline $\mathrm{ScO}_{2}(\%)^{\mathrm{a}}$ & $56 \pm 12^{\mathrm{e}}$ & $68 \pm 13$ & $68 \pm 14^{\mathrm{f}}$ & $54 \pm 12$ \\
\hline $\mathrm{SsO}_{2}(\%)^{\mathrm{c}}$ & $68 \pm 10$ & $63 \pm 7$ & $60 \pm 7$ & $64 \pm 12$ \\
\hline Norepinephrine $(\mathrm{nmol} / \mathrm{L})^{\mathrm{d}}$ & $10.2 \pm 9.2^{\mathrm{h}}$ & $15.1 \pm 7.8$ & $18.4 \pm 6.9$ & $12.6 \pm 8.1$ \\
\hline Epinephrine $(\mathrm{nmol} / \mathrm{L})^{\mathrm{c}}$ & $3.9 \pm 5.7$ & $5.1 \pm 7.1$ & $5.8 \pm 6.9$ & $4.6 \pm 6.7$ \\
\hline
\end{tabular}

$\mathrm{CO}_{2}$, Carbon dioxide; $\mathrm{DO}_{2}$, oxygen delivery; $E R \mathrm{O}_{2}$, oxygen extraction ratio; $Q p$, pulmonary blood flow; $Q s$, systemic blood flow; $S V R$, systemic vascular resistance; $t P V R$, total pulmonary vascular resistance; $\mathrm{PaCO}_{2}$, arterial carbon dioxide tension; $\mathrm{ScO}_{2}$, cerebral oxygen saturation; $\mathrm{SsO}_{2}$, splanchnic oxygen saturation; $\mathrm{PaO}_{2}$, arterial oxygen tension; $\mathrm{SaO}_{2}$, oxygen saturation; $\mathrm{SscO}_{2}$, superior vena cava oxygen saturation; $\mathrm{SpvO}_{2}$, superior pulmonary venous oxygen saturation. Data are mean \pm standard deviation $P$ values (analysis of variance) for any difference during the increases in $\mathrm{PaCO}_{2}:{ }^{\mathrm{a}} P<.0001 ;{ }^{\mathrm{b}} P<.001 ;{ }^{\mathrm{c}} P<.01 ;{ }^{\mathrm{d}} P<.05$. $P$ values (analysis of variance) for the comparisons between 2 sequential stages: ${ }^{\mathrm{e}} P<.0001 ;{ }^{\mathrm{f}} P<.001 ;{ }^{\mathrm{g}} P<.01 ;{ }^{\mathrm{h}} P<.05$.

hemodynamics, oxygen transport, cerebral, and splanchnic circulation in neonates early after the Norwood procedure. The present data demonstrate that a stepwise increase in $\mathrm{PaCO}_{2}$ is not associated with significant changes in tPVR and Qp, whereas a significant decrease in SVR resulted in a significant increase in Qs and $\mathrm{DO}_{2}$. The increase in Qs occurred mainly as a consequence of increased cerebral blood flow, as indicated by increased $\mathrm{ScO}_{2}$ and cerebral arterial blood flow velocity, compromising splanchnic oxygenation, as indicated by a decreased $\mathrm{SsO}_{2}$. The decrease in $\mathrm{VO}_{2}$ further improved the balance of systemic oxygen transport as demonstrated by the significant decrease in $\mathrm{ERO}_{2}$ and arterial lactate. In paradox to the decrease in $\mathrm{VO}_{2}$, plasma norepinephrine and epinephrine increased. This is associated with a small increase in heart rate and arterial blood pressure.

\section{Carbon Dioxide Effects: Pulmonary Versus Systemic Circulation}

$\mathrm{CO}_{2}$ increases pulmonary vascular resistance (PVR) in biventricular circulation, and this has been generally used to explain the mechanisms for the increase in Qs and $\mathrm{DO}_{2}$ in the univentricular and parallel circulation as by decreasing Qp and Qp:Qs. ${ }^{2-5}$ On the basis of this speculation, hypoxia and hypercapnia as potent pulmonary vasoconstrictors were advocated. Although hypoxia fails to improve $\mathrm{DO}_{2}$ and may even be deleterious, ${ }^{3,5}$ induced hypercapnia mostly by hypoventilation remains a common practice aiming to improve $\mathrm{DO}_{2} \cdot{ }^{5,6}$ Although the present data support previous findings, they reveal that the increase in $\mathrm{Qs}$ and $\mathrm{DO}_{2}$ during hypercapnia is due to the direct effect on the systemic circulation rather than the pulmonary circulation. This is supported by little changes in tPVR and Qp. In other words, in the presence of mechanical limitation by the BlalockTaussig shunt, the change in PVR per se plays a limited role to determine tPVR and Qp. We have recently demonstrated that tPVR has little impact on $\mathrm{DO}_{2}$, and that SVR is the most important determinant of $\mathrm{Qs}$ and $\mathrm{DO}_{2}$ in neonates after the Norwood procedure. ${ }^{1}$ It should be remembered that $\mathrm{CO}_{2}$ is also a potent systemic vasodilator via its action on smooth muscle cells and endothelium of peripheral and cerebral arteries. ${ }^{7,8}$ The decrease in SVR and the consequent increase in $\mathrm{Qs}$ and $\mathrm{DO}_{2}$ during hypercapnia are clearly demonstrated in the present data. Systemic afterload reduction with agents such as alpha-blockade phenoxybenzamine nitric oxide donor sodium nitroprusside or a phosphodiesterase III inhibitor milrinone has been increasingly used as a primary management strategy in these patients both before and after the Norwood procedure, with improved postoperative outcomes. ${ }^{13,18-20}$ Therefore, in the concept of optimization of $\mathrm{DO}_{2}$ in the Norwood or single-ventricle physiology, 

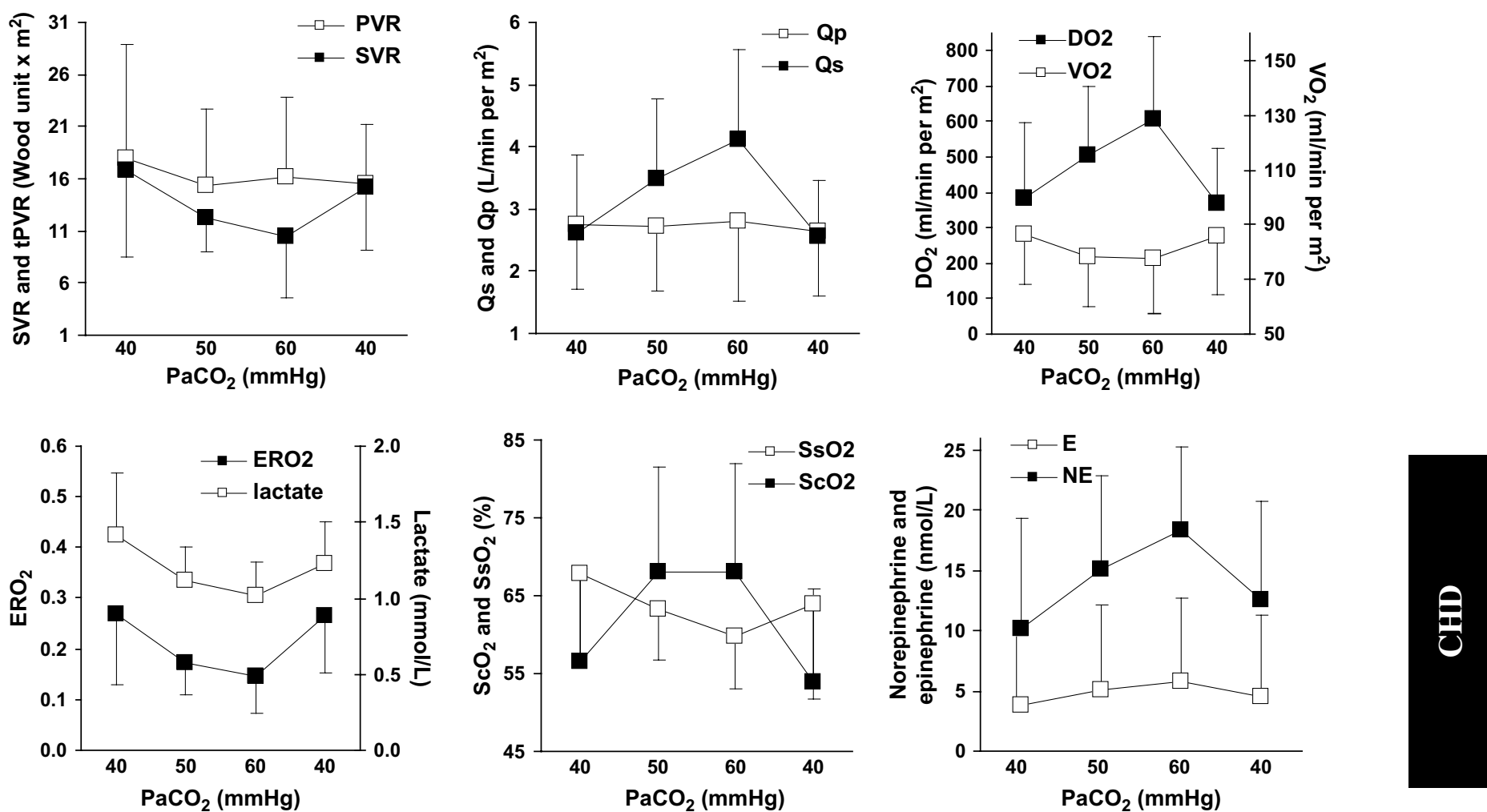

FIGURE 1. Changes (mean \pm standard deviation) in systemic hemodynamics and oxygen transport, including systemic vascular resistance, tPVR, Qp, Qs, $\mathrm{VO}_{2}, \mathrm{DO}_{2}, \mathrm{ERO}_{2}$, lactate, $\mathrm{ScO}_{2}, \mathrm{SsO}_{2}$, and plasma epinephrine and norepinephrine concentration during the stepwise increases in Paco 2 from 40 to 50 to 60 $\mathrm{mm} \mathrm{Hg}$ and after the termination of the additional inspired $\mathrm{CO}_{2}$ at $\mathrm{PaCO}_{2} 40 \mathrm{~mm} \mathrm{Hg}$. $S V R$, Systemic vascular resistance; $t P V R$, total pulmonary vascular resistance; $\mathrm{ERO}_{2}$, oxygen extraction ration; $\mathrm{DO}_{2}$, oxygen delivery; $\mathrm{VO}_{2}$, oxygen consumption; $\mathrm{PaCO}_{2}$, arterial carbon dioxide tension; $\mathrm{ScO}_{2}$, cerebral oxygen saturation; $\mathrm{Ss}_{2}$, splanchnic oxygen saturation; $Q p$, pulmonary blood flow; $Q s$, systemic blood flow.

emphasis should shift from PVR and Qp, even beyond Qp:Qs, directly to SVR and Qs.

In addition, hypercapnia produced a significant increase in $\mathrm{PaO}_{2}$, with no significant change in $\mathrm{SaO}_{2}$ in the present study. This apparent contradiction is likely explained by the fact that increased $\mathrm{PaCO}_{2}$ and acidosis cause a rightward shift in the oxyhemoglobin dissociation curve (Bohr effect), and for any given systemic saturation, $\mathrm{PaO}_{2}$ is higher. The increase in $\mathrm{PaO}_{2}$ may also contribute, to some extent, to the increase in $\mathrm{DO}_{2}$. Indeed, judicious use of higher inspired oxygen fraction has been suggested to improve $\mathrm{DO}_{2}$ in patients undergoing the Norwood procedure. ${ }^{21,22}$ Bradley and colleagues ${ }^{21}$ recently showed an improved $\mathrm{DO}_{2}$ (using indirect indicator of oxygen excess factor) by high inspired oxygen fraction, even with its potent pulmonary vasodilating effect. This further emphasizes the limited contribution of PVR to $\mathrm{DO}_{2}$ in the Norwood circulation.

\section{Carbon Dioxide Effects: Upper Body Versus Lower Body Blood Flow}

All the previous clinical studies have used superior vena caval oxygen saturation as a surrogate of $\mathrm{DO}_{2}$. This could not be completely avoided in the present study; the superior vena caval blood gas was also used as an estimate of the mixed venous oxygen content to calculate SVR and Qs. The derived SVR, Qs, and $\mathrm{DO}_{2}$ in the present study primarily reflect the cerebral vascular bed and may be different from the lower body. ${ }^{23}$ This difference is most likely to be greater in the induced increases in $\mathrm{PaCO}_{2}$, because $\mathrm{CO}_{2}$ is a potent cerebral vasodilator in normal subjects, ${ }^{8}$ as well as in patients after CPB. ${ }^{9,24}$ As a result, the present data, as those in previous clinical studies, may have overestimated the overall changes in SVR, Qs, and $\mathrm{DO}_{2}$ in response to $\mathrm{CO}_{2}$. In animal studies, this limitation was overcome with direct measurement of aortic flow (Qs) using an ultrasonic flow probe placed at the ascending aorta. ${ }^{2-4}$ The percentage of increase in Qs was considerably less when compared with that in our patients $(15 \%$ vs $57 \%)$ for the similar range of $\mathrm{PaCO}_{2}$ changes. ${ }^{2}$ Therefore, caution is needed when interpreting the increase in Qs and $\mathrm{DO}_{2}$ by $\mathrm{CO}_{2}$ in clinical practice as the overall $\mathrm{DO}_{2}$ to the whole body. As further shown in the present data, the increase in Qs at $\mathrm{PaCO}_{2}$ from 40 to $60 \mathrm{~mm}$ $\mathrm{Hg}$ was associated with an increase in $\mathrm{ScO}_{2}$ and a decrease in $\mathrm{SsO}_{2}$, although to a lesser degree $(12 \% \pm 4 \%$ vs $-8 \%$ $\pm 7 \%$ ). It seems that the increase in Qs is primarily the consequence of a significant increase in cerebral blood flow at 
a certain cost of splanchnic perfusion. This is not entirely surprising, considering that the systemic vasodilating effect of $\mathrm{CO}_{2}$ occurs predominately in the brain and to some extent in the heart and nonrespiratory skeletal muscles, whereas little occurs in splanchnic organs. ${ }^{25,26}$ Although ischemic brain injury is a major noncardiac morbidity in patients after the Norwood operation, ${ }^{27,28}$ the increase in cerebral blood flow may be beneficial for brain function; the tradeoff of flow distribution with splanchnic perfusion may be undesirable in these patients. It has been shown that splanchnic organs may be at a higher risk of ischemia because of the lower critical oxygen extraction compared with the other organs; ${ }^{29}$ inadequate splanchnic organ perfusion may be associated with adverse post-CPB outcomes. ${ }^{30}$ It has been reported that gastrointestinal complications are common and related to mortality in patients after the Norwood procedure. ${ }^{31}$ Therefore, it may be unwise to concentrate on maximizing $\mathrm{DO}_{2}$, ignoring regional and tissue perfusion. Further studies are warranted with direct measurements of both superior and inferior vena caval oxygen saturations in addition to NIRS monitoring to provide a clearer picture of $\mathrm{CO}_{2}$ effects on systemic and cerebral and splanchnic $\mathrm{DO}_{2}$.

\section{Carbon Dioxide Effects: Decreased Systemic Oxygen Consumption Versus Increased Circulating Catecholamines}

A significant decrease in $\mathrm{VO}_{2}$ was observed during hypercapnia in neonates after the Norwood procedure. This was accompanied with a significant decrease in central body temperature. This is the second time that this phenomenon has been observed in an intact organism, including animals and humans. The first report was in infants after bidirectional cavopulmonary anastomosis. ${ }^{14}$ Hypercapnic acidosis exerts dual and opposite effects on metabolism and cardiovascular function. ${ }^{14}$ Acidosis (respiratory or metabolic) directly depresses and alkalosis stimulates cellular metabolism in isolated cells and organ. ${ }^{32}$ In intact organisms, acidosis stimulates a significant release of epinephrine and norepinephrine from sympathetic nerve endings and adrenal glands, ${ }^{33,34}$ thus indirectly stimulating metabolism and cardiovascular function. The opposing effects may be essential to maintain metabolic and circulatory homeostasis. It has been shown that myocardia, ${ }^{35}$ cerebral, ${ }^{8}$ and systemic $\mathrm{VO}_{2}{ }^{36,37}$ remain unchanged or slightly increased in subjects with normal biventricular circulation. The mechanisms for the unique decrease in $\mathrm{VO}_{2}$ were speculated in our previous report, ${ }^{14}$ as either reduced metabolic response to or decreased release of catecholamines in the unique circulations. In the present study, plasma epinephrine and norepinephrine were measured. The data showed that the baseline levels of epinephrine and norepinephrine at $\mathrm{PaCO}_{2}$ of $40 \mathrm{~mm} \mathrm{Hg}$ were markedly higher in our patients compared with healthy humans $^{33}$ and infants pre-CPB. ${ }^{38}$ Although it has been well documented that hypothermic CPB for complete correction of congenital heart defects may induce significant increases in circulating epinephrine and norepinephrine, the levels largely return to preoperative baseline at 24 hours. ${ }^{38}$ It is likely that the present group of neonates remained hemodynamically and metabolically stressed longer. It is somewhat surprising the altitude of increases in epinephrine and norepinephrine in our patients is comparable to that in healthy persons over the similar range of $\mathrm{PaCO}_{2}$ increase. ${ }^{33}$ If the release of catecholamines is not the case, the decreased response might be attributable to the deceased $\mathrm{VO}_{2}$ in our patients during hypercapnic acidosis. CPB may decrease the metabolic response to catecholamines. ${ }^{39}$ The mechanism for the paradoxic changes in $\mathrm{VO}_{2}$ and circulating catecholamines remains unclear, and the clinical implication of the increased circulating catecholamines on cardiovascular function is uncertain. A small increase in heart rate and systemic arterial blood pressure was observed that is consistent with previous findings. ${ }^{33,36}$ Any increase in cardiovascular work load might be undesirable in these post-Norwood neonates with marginal reserve of cardiovascular function. In addition, $\alpha$-adrenergic receptor stimulation in the splanchnic vascular bed by epinephrine and norepinephrine may reduce the regional blood flow. ${ }^{40}$ This might be partly attributable to the decrease in $\mathrm{SsO}_{2}$.

\section{Study Limitations}

The order of exposure to the different $\mathrm{CO}_{2}$ tensions was not randomized. However, it is unlikely that the findings were due merely to the sequence of changes because the final $\mathrm{CO}_{2}$ level of $40 \mathrm{~mm} \mathrm{Hg}$ demonstrated a reversal of changes noted with each previous sequential increase in $\mathrm{CO}_{2}$ tension.

The changes were monitored for 30 minutes at each level of $\mathrm{PaCO}_{2}$, and therefore we could not address the effects of prolonged or severe hypercapnia. The use of superior vena caval blood as an estimation of the mixed venous gas for the calculations of SVR, Qs, and $\mathrm{DO}_{2}$ may be a limitation and was discussed above.

NIRS was used to estimate cerebral and splanchnic oxygenation in our study. As mentioned above, NIRS measures oxygen saturation in the mixture of arteries, capillaries, and veins in a small part of underlining tissue and thus may not precisely reflect the overall balance of cerebral or splanchnic oxygen transport or precisely measure the regional blood flow or $\mathrm{DO}_{2}$. Nonetheless, in the patients who were sedated and paralyzed, $\mathrm{VO}_{2}$ was minimized. The change in regional oxygen saturation as measured by NIRS may largely reflect the changes in regional blood flow and $\mathrm{DO}_{2}$ (ie, in the brain and splanchnic organs) in our current study.

\section{CONCLUSIONS}

$\mathrm{CO}_{2}$ exerts complex effects on systemic and regional oxygen transport in neonates after the Norwood procedure. 
Moderate hypercapnia with acidosis increases Qs and $\mathrm{DO}_{2}$ via the direct systemic vasodilatation effect, rather than the effect on pulmonary vasoconstriction as previously proposed. The increase in Qs and $\mathrm{DO}_{2}$ is primarily the consequence of increase cerebral blood flow, with an undesirable tradeoff of splanchnic oxygenation. In addition, $\mathrm{CO}_{2}$ decreases $\mathrm{VO}_{2}$, contributing to the balance of systemic oxygen transport. The implication of the increase in circulating catecholamines remains uncertain. Clinical use of $\mathrm{CO}_{2}$ aiming to improve $\mathrm{DO}_{2}$ in patients with univentricular and parallel circulation should be with caution. Our data ask further understanding of oxygen transport, not only at the systemic level but also at the regional and tissue level, when designing any intervention aiming to improve oxygen status in critically ill patients after CPB.

\section{References}

1. Li J, Zhang G, Holtby HM, McCrindle BW, Cai S, Humpl T, et al. Profiles of hemodynamics and oxygen transport derived using continuous measured oxygen consumption following the Norwood procedure. J Thorac Cardiovasc Surg. 2007;133:441-8.

2. Mora GA, Pizarro C, Jacobs ML, Norwood WI. Experimental model of single ventricle. Influence of carbon dioxide on pulmonary vascular dynamics. Circulation. 1994;90:II43-6.

3. Reddy VM, Liddicoat JR, Fineman JR, McElhinney DB, Klein JR, Hanley FL. Fetal model of single ventricle physiology: hemodynamic effects of oxygen, nitric oxide, carbon dioxide, and hypoxia in the early postnatal period. J Thorac Cardiovasc Surg. 1996;112:437-49.

4. Riordan CJ, Randsbeck F, Storey JH, Montgomery WD, Santamore WP, Austin EH III. Effects of oxygen, positive end-expiratory pressure, and carbon dioxide on oxygen delivery in an animal model of the univentricular heart. J Thorac Cardiovasc Surg. 1996;112:644-54.

5. Bradley SM, Simsic JM, Atz AM. Hemodynamic effects of inspired carbon dioxide after the Norwood procedure. Ann Thorac Surg. 2001;72:2088-93.

6. Tabbutt S, Ramamoorthy C, Montenegro LM, Durning SM, Kurth CD, Steven JM, et al. Impact of inspired gas mixtures on preoperative infants with hypoplastic left heart syndrome during controlled ventilation. Circulation. 2001;104:I159-64.

7. Fukuda S, Matsumoto M, Nishimura N, Fujiwara N, Shimoji K, Takeshita H, et al. Endothelial modulation of norepinephrine-induced constriction of rat aorta at normal and high C02 tensions. Am J Physiol. 1990;258:H104954.

8. Kety SS, Schmidt CF. The effects of altered arterial tensions of carbon dioxide and oxygen on cerebral blood flow and cerebral oxygen consumption of normal young man. J Clin Invest. 1948;27:484-92.

9. Hoskote A, Li J, Hickey C, Erickson S, Van Arsdell G, Stephens D, et al. The effects of carbon dioxide on oxygenation, systemic, cerebral and pulmonary vascular hemodynamics after the bidirectional superior cavopulmonary anastomosis. J Am Coll Cardiol. 2004;6(44):1501-9.

10. Wyatt JS, Cope M, Delpy DT, Wray S, Reynolds EO. Quantification of cerebral oxygenation and haemodynamics in sick newborn infants by near infrared spectrophotometry. Lancet. 1986;2:1063-6.

11. Petros AJ, Heys R, Tasker RC, Fortune PM, Roberts I, Kiely E. Near infrared spectroscopy can detect changes in splanchnic oxygen delivery in neonates during apnoeic episodes. Eur J Pediatr. 1999;158:173-4.

12. Li J, Zhang G, Benson L, Holtby H, Cai S, Humpl T, et al. Comparison of the profiles of postoperative systemic hemodynamics and oxygen transport in neonates after the hybrid or the Norwood procedure: a pilot study. Circulation. 2007; 116(11 Suppl):I179-87.

13. De Oliveira NC, Van Arsdell GS. Practical use of alpha blockade strategy in the management of hypoplastic left heart syndrome following stage one palliation with a Blalock-Taussig shunt. Semin Thorac Cardiovasc Surg Pediatr Card Surg Anпи. 2004;7:11-5

14. Li J, Hoskote A, Hickey C, Van Arsdell G, Redington A, Adatia I. Hypercapnia improves systemic oxygenation and decreases oxygen consumption and blood lactate levels in children after bidirectional cavopulmonary shunt operation. Crit Care Med. 2005;33:984-9.

15. $\mathrm{Li} \mathrm{J}$, Redington $\mathrm{AN}$. Unique technique for assessing the effects of $\mathrm{CO}_{2}$ on oxygen transport variables. J Intensive Care Med. 2006;13:169-75.

16. Li J, Van Arsdell GS, Zhang G, Cai S, Humpl T, Caldarone CA, et al. Assessment of the relationship between cerebral and splanchnic oxygen saturations measured by near-infrared spectroscopy and direct measurements of systemic haemodynamic variables and oxygen transport after the Norwood procedure. Heart. 2006;92:1678-85.

17. Musso NR, Vergassola C, Pende A, Lotti G. Reversed-phase HPLC separation of plasma norepinephrine, epinephrine, and dopamine, with three-electrode coulometric detection. Clin Chem. 1989;35:1975-7.

18. Stieh J, Fischer G, Scheewe J, Uebing A, Dutschke P, Jung O, et al. Impact of preoperative treatment strategies on the early perioperative outcome in neonates with hypoplastic left heart syndrome. J Thorac Cardiovasc Surg. 2006;131: 1122-9.

19. De Oliveira NC, Ashburn DA, Khalid F, Burkhart HM, Adatia IT, Holtby HM, et al. Prevention of early sudden circulatory collapse after the Norwood operation. Circulation. 2004;110:II133-8.

20. Tweddell JS, Hoffman GM, Fedderly RT, Berger S, Thomas JP Jr, Ghanayem NS, et al. Phenoxybenzamine improves systemic oxygen delivery after the Norwood procedure. Ann Thorac Surg. 1999;67:161-7.

21. Bradley SM, Atz AM, Simsic JM. Redefining the impact of oxygen and hyperventilation after the Norwood procedure. J Thorac Cardiovasc Surg. 2004;127: 473-80.

22. Taeed R, Schwartz SM, Pearl JM, Raake JL, Beekman RH III, Manning PB, et al. Unrecognized pulmonary venous desaturation early after Norwood palliation confounds Qp:Qs assessment and compromises oxygen delivery. Circulation. 2001; 103:2699-704

23. Scheinman MM, Brown MA, Rapaport E. Critical assessment of use of central venous oxygen saturation as a mirror of mixed venous oxygen in severely ill cardiac patients. Circulation. 1969;40:165-72.

24. Cheng W, Hartmann JF, Cameron DE, Griffiths EM, Kirsch JR, Traystman RJ. Cerebral blood flow during cardiopulmonary bypass: influence of temperature and pH management strategy. Ann Thorac Surg. 1995;59:880-6.

25. Kiefer P, Nunes $\mathrm{S}$, Kosonen $\mathrm{P}$, Takala J. Effect of an acute increase in $\mathrm{PCO}_{2}$ on splanchnic perfusion and metabolism. Intensive Care Med. 2001;27: $775-8$.

26. Davidson D, Stalcup SA, Mellins RB. Systemic hemodynamics affecting cardiac output during hypocapnic and hypercapnic hypoxia. J Appl Physiol. 1986;60: 1230-6.

27. Dent CL, Spaeth JP, Jones BV, Schwartz SM, Glauser TA, Hallinan B, et al. Brain magnetic resonance imaging abnormalities after the Norwood procedure using regional cerebral perfusion. J Thorac Cardiovasc Surg. 2006;131: 190-7.

28. Hoffman GM, Mussatto KA, Brosig CL, Ghanayem NS, Musa N, Fedderly RT, et al. Systemic venous oxygen saturation after the Norwood procedure and childhood neurodevelopmental outcome. J Thorac Cardiovasc Surg. 2005;130: 1094-100.

29. Nelson DP, King CE, Dodd SL, Schumacker PT, Cain SM. Systemic and intestinal limits of 02 extraction in the dog. J Appl Physiol. 1987;63:387-94.

30. Perez A, Schnitzler EJ, Minces PG. The value of gastric intramucosal $\mathrm{pH}$ in the postoperative period of cardiac surgery in pediatric patients. Crit Care Med. 2000;28:1585-9.

31. Jeffries HE, Wells WJ, Starnes VA, Wetzel RC, Moromisato DY. Gastrointestinal morbidity after Norwood palliation for hypoplastic left heart syndrome. Ann Thorac Surg. 2006;81:982-7.

32. Canzanelli A, Greenblatt M, Rogers GA, Rapport D. The effect of $\mathrm{pH}$ changes on the in-vitro 02 consumption of tissues. Am J Physiol. 1939;127:290-5.

33. Sechzer PH, Egbert LD, Linde HW, Cooper DY, Dripps RD, Price HL. Effect of carbon dioxide inhalation on arterial pressure, ECG and plasma catecholamines and 17-OH corticosteroids in normal man. J Appl Physiol. 1960;15:454-8.

34. Low JM, Gin T, Lee TW, Fung K. Effect of respiratory acidosis and alkalosis on plasma catecholamine concentrations in anaesthetized man. Clin Sci (Lond). 1993;84:69-72.

35. Rasmussen JP, Dauchot PJ, DePalma RG, Sorensen B, Regula G, Anton AH, et al. Cardiac function and hypercarbia. Arch Surg. 1978;113:1196-200.

36. Nahas GG, Ligou JC, Mehlman B. Effects of $\mathrm{pH}$ changes on 02 uptake and plasma catecholamine levels in the dog. Am J Physiol. 1960;198:60-6.

37. Thorens JB, Jolliet P, Ritz M, Chevrolet JC. Effects of rapid permissive hypercapnia on hemodynamics, gas exchange, and oxygen transport and consumption 
during mechanical ventilation for the acute respiratory distress syndrome. Intensive Care Med. 1996;22:182-91.

38. Gruber EM, Laussen PC, Casta A, Zimmerman AA, Zurakowski D, Reid R, et al. Stress response in infants undergoing cardiac surgery: a randomized study of fentanyl bolus, fentanyl infusion, and fentanyl-midazolam infusion. Anesth Analg. 2001;92:88-90.
39. Smiley RM, Vulliemoz Y. Cardiac surgery causes desensitization of the betaadrenergic receptor system of human lymphocytes. Anesth Analg. 1992;74: 212-8.

40. Duranteau J, Sitbon P, Teboul JL, Vicaut E, Anguel N, Richard C, et al. Effects of epinephrine, norepinephrine, or the combination of norepinephrine and dobutamine on gastric mucosa in septic shock. Crit Care Med. 1999;27:893-900. 